\title{
Effects of Postnatal Maturation on Postrest Potentiation in Isolated Rabbit Atria
}

\author{
ROBERT J. BOUCEK, JR., MICHAEL CITAK, THOMAS P. GRAHAM, JR., AND \\ MICHAEL ARTMAN \\ WITH THE TECHNICAL ASSISTANCE OF EVELYN OKEDIJI \\ Departments of Pediatrics and Biochemistry, Vanderbilt University School of Medicine, \\ Nashville, Tennessee 37232
}

\begin{abstract}
Ultrastructural changes in cardiac sarcoplasmic reticulum (SR) have been reported during postnatal development of the mammalian heart, but the functional significance of these observations has not been well characterized. Calcium release from $S R$ in intact myocardial preparations was determined by the contractile characteristics of postrest contractions. Isometric tension and the maximum rate of tension development of the first contraction following intervals of electromechanical quiescence (rest) were related to steady-state tension and maximum rate of tension development during contraction at constant frequency $(1.0 \mathrm{~Hz})$ in isolated left atrial strips from newborn (1-7 days), immature (14-21 days), and adult (more than 6 months) rabbits. The first postrest contraction was increased as a function of the rest interval rate of tension development, defined as postrest potentiation, in all three age groups and reached a maximum value at rest intervals of more than $20 \mathrm{~s}$. Tension developed by the first contraction following a 60 -s rest interval was potentiated less in newborn and immature atria than in adult atria at an extracellular calcium concentration $\left([\mathrm{Ca}]_{\mathrm{e}}\right)$ of $2.5 \mathrm{mM}$, an age-related difference most marked in the immature. Ryanodine $\left(5.0 \times 10^{-9} \mathrm{M}\right)$, a putative blocker of calcium release from cardiac $\mathrm{SR}$, abolished postrest potentiation providing evidence that calcium release from $S R$ is the predominant determinant of the postrest contraction. Postrest tension in atria from the immature rabbit heart was significantly increased both in absolute terms and relative to steady-state tension following stabilization under conditions which increase intracellular $[\mathrm{Ca}]\left([\mathrm{Ca}]_{i}\right)$, i.e. increasing $[\mathrm{Ca}]_{e}$, increasing tonicity, or decreasing extracellular sodium concentration $\left([\mathrm{Na}]_{e}\right)$. In contrast, postrest tension in atria from the adult rabbit heart decreased relative to steady-state tension under conditions that increase $[\mathrm{Ca}]_{\text {i. }}$. Rest potentiated contraction to a similar extent in both age groups (approximately $300 \%$ of steady-state) but this maximum was obtained under markedly different ionic conditions. Maximum postrest potentiation occurred at $2.5 \mathrm{mM}$ $[\mathrm{Ca}]_{\mathrm{e}}$ and $153.0 \mathrm{mM}[\mathrm{Na}]_{\mathrm{e}}$ in the adult atria whereas maximum potentiation occurred at $5.0 \mathrm{mM}[\mathrm{Ca}]_{\mathrm{e}}$ and $87.0 \mathrm{mM}[\mathrm{Na}]_{\mathrm{e}}$ in immature atria. Results from experiments in which $[\mathrm{Ca}]_{\mathrm{e}}$ was increased during a 60 -s rest interval suggest that the predominant effects of $[\mathrm{Ca}]_{e}$ on postrest potentiation are attributable to $[\mathrm{Ca}]_{\mathrm{e}}$-dependent changes in $[\mathrm{Ca}]_{i}$ as opposed to rest-dependent changes in
\end{abstract}

Received April 24, 1986; accepted June 22, 1987.

Supported in part by American Heart Association (Tennessee Affiliate) and The March of Dimes Foundation.

Correspondence Robert J. Boucek, Jr., M.D., Division of Pediatric Cardiology, Department of Pediatrics D-2217, Vanderbilt University Medical Center, Nashville, TN 37232. transmembrane calcium conductance. These results lead us to conclude that in rabbit atria: 1) contractile calcium released from the $S R$ is demonstrated and therefore may potentially participate in excitation-contraction coupling during postnatal development; 2) the contribution of calcium released from the $S R$ to contractile calcium during steady-state contraction may be less during early cardiac development; 3) the age-related differences in postrest contraction can be abolished by manipulating ionic conditions to increase $[\mathrm{Ca}]_{i}$ indicating that the immature $\mathrm{SR}$ requires higher $[\mathrm{Ca}]_{i}$ for optimal calcium loading and/or "triggered" release of calcium than does SR in the adult. (Pediatr Res 22: 524-530, 1987)

\section{Abbreviations}

SR, sarcoplasmic reticulum

$T$, developed tension

$+\mathrm{dT} / \mathrm{dt}$, maximum rate of tension development

$[\mathrm{Ca}]_{i}$, intracellular concentration of calcium

$[\mathrm{Ca}]_{\text {e, }}$ extracellular concentration of calcium

ANOVA, analysis of variance

The SR plays a predominant role in the regulation of calcium in mature mammalian myocardium $(1,2)$. Calcium released from the SR in ventricular cardiomyocytes is thought to be the major source of contractile calcium, i.e. calcium that activates the interaction of the contractile proteins (1). Despite the apparent importance of calcium release from SR as a source of contractile calcium, little is known about the development of this specialized property of the SR. Quantitative morphometric analyses of the developing mammalian heart have shown significant structural changes of the SR and T-tubule system during the postnatal period (3-5). Absence of calcium release from the $\mathrm{SR}$ in the newborn rat heart has suggested that calcium release develops postnatally (1). Analyses of age-related differences in contractile responses to calcium channel blockade $(6,7)$ and cellular electrophysiologic properties (4) have suggested that transsarcolemmal calcium influx, rather than calcium release from the SR, may be the most significant source of contractile calcium during postnatal development. The purposes of this study were to determine if calcium release from the SR can be demonstrated in the developing heart and, if present, to characterize the properties of calcium release by the SR during postnatal cardiac development.

Atrial postrest contraction was selected as an experimental approach for age-related comparisons of calcium release from the SR in intact contractile tissue (8). In atria, force development of the first contraction following a period of rest less than $120 \mathrm{~s}$ 
is potentiated. Postrest potentiation of contraction is due predominantly to increased calcium loading and release by intracellular stores, presumably from the SR (9-12). This study characterized postrest contraction in the left atria isolated from rabbit heart in order to evaluate postnatal maturation of SR calcium release. Postrest contraction of atrial strips from the adult, or mature, rabbit heart were compared to postrest contraction of atrial strips from rabbit hearts at two age groups during postnatal development. The newborn ( $1-7$ days old) age group was selected because of evidence suggesting little or no participation of SR in contraction $(1,4)$. The immature (14-21 days old) age group was selected because of evidence suggesting limited participation of the SR in contraction $(6,7)$.

\section{METHODS}

Isolated contracting left atrial strip. Left atria were removed from the hearts of newborn (1-7 days old; 15-40 g), immature (14-21 days old; $200-400 \mathrm{~g}$ ), and adult (more than 6 months; 3 $\mathrm{kg}$ ) New Zealand White rabbits killed by cervical dislocation. A single comparably sized strip was cut from the left atrium and suspended vertically in a muscle bath containing Krebs-bicarbonate buffer ( $\mathrm{pH} 7.4$ ) with the following composition: $\mathrm{NaCl}$ (127 mmol/liter); $\mathrm{KCl}(2.3 \mathrm{mmol} /$ liter $) ; \mathrm{KH}_{2} \mathrm{PO}_{4}(1.3 \mathrm{mmol} /$ liter; $\mathrm{MgSO}_{4}$ (0.6 mmol/liter); $\mathrm{CaCl}_{2}(2.5 \mathrm{mmol} /$ liter $) ; \mathrm{NaHCO}_{3}$ $(25.0 \mathrm{mmol} / \mathrm{liter})$, and glucose $(5.5 \mathrm{mmol} / \mathrm{liter})$. The bath was filled with $25 \mathrm{ml}$ of buffer which was continuously bubbled with $95 \% \mathrm{O}_{2} / 5 \% \mathrm{CO}_{2}(\mathrm{v} / \mathrm{v})$ and maintained at $30^{\circ} \mathrm{C}$. The base of the atrial strip was held stationary by a clip containing two punctate platinum electrodes. The top of the muscle was sutured to a fine gold chain and suspended from a precalibrated force transducer (Gould-Statham UC3). Atrial strips were electrically stimulated (Grass model 588) to contract at a frequency of $1 \mathrm{~Hz}(60 / \mathrm{min})$ using square wave pulses of $3 \mathrm{~ms}$ duration at a voltage $10 \%$ above threshold. Resting tension was the measured tension at any given length immediately prior to each electrically stimulated contraction.

Peak isometric and resting tensions were continuously recorded on Gould Model 220 strip-chart recorder. T was defined as the difference between resting and peak tensions. $+\mathrm{dT} / \mathrm{dt}$ was obtained by averaging the slopes of tangents drawn to the tension tracings at the point of maximum positive change (chart speed of $125 \mathrm{~mm} / \mathrm{s}$ ).

Each atrial strip was allowed to stabilize while isometrically contracting at $1 \mathrm{~Hz}$ for $1 \mathrm{~h}$, during which time the length was gradually increased until resting tensions were approximately comparable for newborn and immature and for adult atrial strips of approximately comparable size. Classical length-tension curves cannot be reliably achieved with isolated atrial strips without overstretching (in contrast to papillary muscles), presumably due to the nonparallel fiber array of atrial muscle strips. However, preliminary experiments indicated that these developed tensions for the size strips used in these experiments approximated near-maximal basal developed tensions for the respective age groups. This length was maintained constant throughout each experiment. Resting tension for the immature group was slightly less than the adult group (Table $1 ; p<0.05$ ). Resting tension decreased slightly throughout the experimental period in each age group, a characteristic typical of atrial preparations. All atrial strips were continuously stimulated at $1 \mathrm{~Hz}$ throughout the experimental period except during the brief rest intervals.

Steady-state contractile parameters were always determined after stabilization at $1 \mathrm{~Hz}$ stimulation rate. Representative steadystate contractile parameters of atrial strips from the three age groups evaluated in this study are given in Table 1 .

Postrest contraction. Termination of electrical stimulation initiated the rest interval during which no spontaneous contractions occurred, i.e. electromechanical quiescence. Reinitiation of electrically stimulated contraction at $1 \mathrm{~Hz}$ following rest intervals
Table 1. Steady-state contractile parameters

\begin{tabular}{lccr}
\hline & $\begin{array}{c}\text { Resting } \\
\text { tension }(\mathrm{g})\end{array}$ & $\mathrm{T}(\mathrm{g})$ & $+\mathrm{dT} / \mathrm{dt}(\mathrm{g} / \mathrm{s})$ \\
\hline Newborn $(n=14)$ & $0.38 \pm 0.03$ & $0.12 \pm 0.03$ & $0.179 \pm 0.05$ \\
Immature $(n=18)$ & $0.37 \pm 0.03$ & $0.18 \pm 0.03$ & $0.337 \pm 0.06$ \\
Adult $(n=16)$ & $0.47 \pm 0.03$ & $0.41 \pm 0.07$ & $1.23 \pm 0.32$ \\
\hline
\end{tabular}

resulted in a characteristic increase in $\mathrm{T}$ and $+\mathrm{dT} / \mathrm{dt}$ of the first postrest contraction $\left(R_{1}\right)$. Postrest potentiation was defined as the increase in $R_{1}$ contraction indices $\mathrm{T}$ or $+\mathrm{dT} / \mathrm{dt}$ expressed as percent of the prerest steady-state values.

Atrial tissue was selected to assess the postnatal development of calcium release from the SR for two primary reasons. First, current evidence suggests that the junctional face of the SR associated with either the external sarcolemmal membrane or the $\mathrm{T}$-tubule system are the sites of calcium release from SR. Calcium release mechanisms may differ in SR junctionally associated with the T-tubule system from those in SR junctionally associated with the external sarcolemmal membrane. In ventricular tissue there is significant postnatal development of the junctional association between the SR and the T-tubule system coincident with a decrease in junctional SR associated with the sarcolemma (3-5). Thus studying the postnatal development of the SR in atrial tissue is not complicated by concurrent development of the SR/T-tubule junction since the T-tubule system is sparse in atria and the atrial SR is junctionally associated with the sarcolemma throughout postnatal development (5). Further support for this rationale published during the course of this study was the suggestion by other investigators that the postnatal development of the T-tubule system may significantly affect postrest contraction in ventricular tissue (13). The second reason for selecting atrial tissue for this study is that tension development of the first contraction following rest is greater than steady-state tension development in atria $(9-12)$. Postrest potentiation in atrial tissue has been related to a net increase in calcium loading of the SR during the rest interval leading to greater calcium release upon resumption of stimulation. In contrast, with adult rabbit ventricular tissue there is time-dependent decrease in $R_{1}$ $T$ (11, 13-15; personal observation) during the rest interval suggesting a rest time-dependent depletion in intracellular calcium stores in ventricular tissue (15). Thus the postrest tensionrest interval relationship in ventricular tissue would be expected to reflect not only calcium loading and "triggered" calcium release from SR but also this time-dependent calcium "leak," a confounding variable not present in atrial tissue.

Effect of ryanodine on steady-state and postrest contraction. Ryanodine (Penick Corp., Lyndhurst, $\mathrm{NJ}$ ) was the gift of Dr. Sidney Fleischer (Department of Molecular Biology, Vanderbilt University). The effect of two concentrations of ryanodine (1.0 and $5.0 \times 10^{-9} \mathrm{M}$ ) on steady-state and $\mathrm{R}_{1} \mathrm{~T}$ and $+\mathrm{dT} / \mathrm{dt}$ was evaluated at $5.0 \mathrm{mM}[\mathrm{Ca}]_{\mathrm{c}}$ (the $[\mathrm{Ca}]_{\mathrm{c}}$ resulting in maximal postrest potentiation in immature atrial strips). In preliminary experiments, $5 \times 10^{-9} \mathrm{M}$ ryanodine blocked postrest potentiation with minimal inhibition of steady-state contraction. However, to ensure in each individual experiment that the ryanodine concentration was the lowest concentration required to inhibit postrest potentiation without inhibiting steady-state contraction, ryanodine was first added at a 5-fold lower concentration $\left(10^{-9} \mathrm{M}\right)$. With careful attention to time, the second ryanodine dose was added to the bath to achieve the desired final concentration $(5 \times$ $\left.10^{-9} \mathrm{M}\right)$. Prior to, 15 , and $30 \mathrm{~min}$ after each of the two additions of ryanodine to the muscle bath the developed tension, $+\mathrm{dT} / \mathrm{dt}$, time-to-peak, $90 \%$ relaxation time, and resting tension were determined at steady-state $(1 \mathrm{~Hz})$ and following a 60 -s rest interval $\left(R_{1}\right)$. In all instances, the lower concentration of ryanodine $\left(10^{-9} \mathrm{M}\right)$ failed to completely block postrest potentiation (data not shown). Cumulative ryanodine dose response studies 
were not performed because of significant time-dependent effects of ryanodine on contraction (17).

Effects of $[\mathrm{Ca}]_{e},[\mathrm{Na}]_{e}$, and tonicity on postrest contraction. $\mathrm{R}_{1}$ contractile responses to rest intervals of $5,10,10,30,60$, and 90 $\mathrm{s}$ were evaluated in atrial strip at four extracellular calcium concentrations: $2.5,5.0,7.5$, and $10 \mathrm{mM}$. Atrial strips were allowed to restabilize to steady-state for $10-15 \mathrm{~min}$ after each change in $[\mathrm{Ca}]_{e}$ and between each rest interval trial. In certain experiments the effect of incremental increases in [Ca $]_{e}$ during a 60-s rest interval on the $R_{1}$ contractile responses was determined. In these experiments microliter aliquots of a concentrated calcium stock solution were added to the muscle bath during the first $5 \mathrm{~s}$ of the $60 \mathrm{sec}$ rest interval, thereby increasing $[\mathrm{Ca}]_{\mathrm{e}}$ by an increment of $2.5 \mathrm{mM}$.

Tonicity of the bath solution was increased by the addition of sucrose to increase the osmolality of the standard Krebs-bicarbonate buffer to that equivalent to $196 \mathrm{mM}[\mathrm{Na}]_{\mathrm{e}}$. Steady-state and 60 -s postrest contractile responses were also evaluated at a lower $[\mathrm{Na}]_{\mathrm{e}}$ in immature and adult atrial strips. To minimize osmotic effects while reducing $[\mathrm{Na}]_{e}$, additional sucrose was added to the hypertonic Krebs-bicarbonate buffer to maintain osmolality equivalent to that of $196 \mathrm{mM} \mathrm{[Na}]_{e}$, as described by Tillisch et al. (18). Therefore, for these experiments, steady-state and postrest contractile responses were determined at both "low" $(87 \mathrm{mM})$ and "control" $(153 \mathrm{mM})$ sodium concentrations in the hypertonic Krebs-bicarbonate buffer. Contractile responses to "low" [ $\mathrm{Na}]_{\mathrm{e}}$ reported herein are $30 \mathrm{~min}$ after reducing $[\mathrm{Na}]_{\mathrm{e}}$, the time that approximated the maximum increase in steady-state $\mathrm{T}$. The postrest contractile responses were compared to the steady-state contractile force developed at the respective [ $\mathrm{Na}]_{\mathrm{e}}$ (in the presence of sucrose) recorded immediately prior to the rest interval.

Statistical analyses. Results are expressed as the mean $\pm \mathrm{SE}$. Comparisons between the postrest and the steady-state contraction are expressed both in absolute values and as the percentage change from preceding steady-state to the first postrest beat. Since $R_{1} T$ and $+d T / d t$ always demonstrated equivalent responses, only $R_{1} T$ is displayed in order to simplify the presentation. Comparisons between the postrest and the steady-state contraction were performed by means of an unpaired Student's $t$ test. Comparisons between adult and immature groups were performed using an unpaired $t$ test. Comparisons between the newborn, immature, and adult groups were performed using a one-way ANOVA for unequal sized samples. Comparisons of the effects of the addition of calcium during the rest period, the increase in bath tonicity, and the decrease in $[\mathrm{Na}]_{\mathrm{e}}$ were evaluated by means of a paired Student's $t$ test. The two-tailed probability level of significance was $p \leq 0.05$.

\section{RESULTS}

The steady-state values for resting tension, $\mathrm{T}$, and $+\mathrm{dT} / \mathrm{dt}$ are shown in Table 1. Both the magnitude (Fig. 1) and rate (data not shown) of tension development were increased as the rest interval was increased reaching a maximum following $60 \mathrm{~s}$ of rest in all three age groups. The relationship between $R_{1}$ contractile force and the rest interval (s) was evaluated at rest intervals from 5 to $90 \mathrm{~s}$ in all three age groups and at different $[\mathrm{Ca}]_{\mathrm{e}}$. In all circumstances this relationship reached a plateau value by 20 $s$; hence most comparisons of $R_{1}$ values shown in the test were after a 60 -s rest period and are abbreviated as $R_{1} 60$ values.

A representative tracing of postrest potentiation is shown in Figure $2 A$. The magnitude of the postrest contraction following $60 \mathrm{~s}$ of rest, $\mathrm{R}_{1} 60 \mathrm{~T}$, was significantly more potentiated in atrial strips from the adult hearts than either the newborn and immature (Fig. $2 B$ ) in standard Krebs-bicarbonate buffer containing $2.5 \mathrm{mM}[\mathrm{Ca}]_{\mathrm{e}}$. Postrest potentiation was 222,181 , and $306 \%$ of steady-state $T$ for the newborn, immature and adult atrial strips, respectively, (newborn versus adult, $p<0.05$; im-

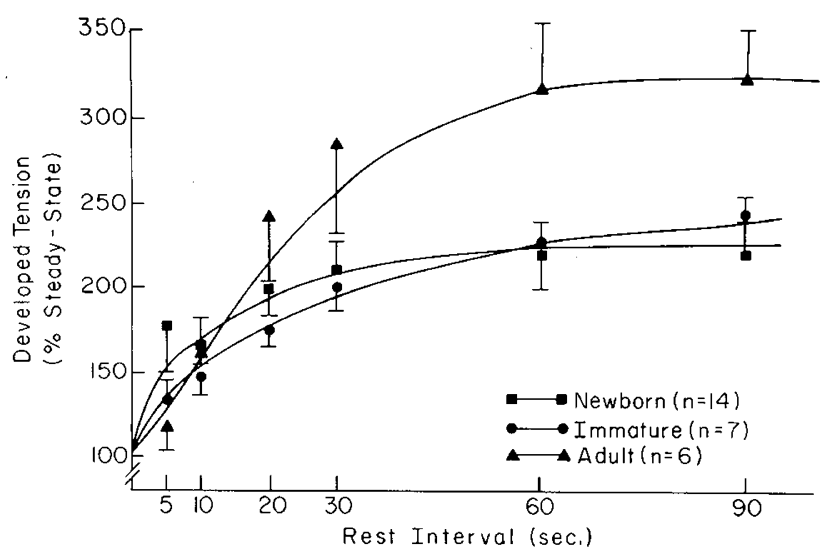

Fig. 1. Effects of rest on the tension developed by the first postrest contraction. Left atrial strips from newborn, immature, and adult rabbit hearts contracting at $1 \mathrm{~Hz}$ were rested for intervals between 5 and $90 \mathrm{~s}$. The developed tension of the first contraction after the rest interval is expressed as the percent of the steady-state developed tension immediately prior to the rest interval. $[\mathrm{Ca}]_{e}$ was $2.5 \mathrm{mM}$.

mature versus adult, $p<0.01$ ). The rate of tension development, $\mathrm{R}_{1} 60 \mathrm{dT} / \mathrm{dt}$, was also more potentiated by rest in the adult than the immature atrial strips (Fig. 2C). Rest potentiation of $+\mathrm{dT} /$ $\mathrm{dt}$ was 161 and $327 \%$ of steady-state $\mathrm{dT} / \mathrm{dt}$ for immature and adult atrial strips $(p<0.05)$. $\mathrm{R}_{1} 60 \mathrm{dT} / \mathrm{dt}$ was not significantly different between atrial strips from the adult and newborn heart. Resting tension of the postrest contractions were not different from steady-state resting tension (Table 1) in the three age groups studied. Because of these qualitative similarities in the age-related differences in postrest contraction of the newborn and immature atrial strips subsequent age-related comparisons of postrest contraction were evaluated more fully in the immature (14-21 day old) and the adult age groups.

Steady-state and postrest T (Figs. 3 and 4) increased in response to an increase in $[\mathrm{Ca}]_{\mathrm{e}}$ but with significant age-related differences. Rest potentiated contraction was in the immature than in the adult atrial strips at $2.5 \mathrm{mM}[\mathrm{Ca}]_{\mathrm{e}}$. $\mathrm{R}_{1} 60 \mathrm{~T}$ was 176 and $287 \%$ of steady-state tension in immature and adult atrial strips respectively $(p<0.05$; Fig. 4). Following an incremental increase in [Ca $]_{\mathrm{e}}$ from 2.5 to $5.0 \mathrm{mM}$ in immature atrial strips, both $\mathrm{R}_{1} 60$ $T$ increased (Fig. 3) and postrest potentiation increased relative to the $[\mathrm{Ca}]_{\mathrm{e}}$-dependent increase in steady-state $\mathrm{T}$ (Fig. 4). Further increases in $[\mathrm{Ca}]_{\mathrm{e}}$ did not increase rest potentiation $\mathrm{R}_{1} 60 \mathrm{~T}$ in immature atrial strips (Fig. 4). With incremental increases in $[\mathrm{Ca}]_{\mathrm{e}}$ up to $10.0 \mathrm{mM}$, there were small increases in $\mathrm{R}_{1} 60 \mathrm{~T}$ and a larger increase in steady-state $\mathrm{T}$ in adult atrial strips (Fig. 3). Therefore postrest potentiation actually decreased in adult atrial strips due to the larger $[\mathrm{Ca}]_{e}$-dependent increase in steady-state $T$ (Fig. 4) relative to $R_{1} 60 \mathrm{~T}$.

In the preceding experiments, $[\mathrm{Ca}]_{e}$ was increased during stimulation at $1 \mathrm{~Hz}$. Steady-state $T$ and $+\mathrm{dT} / \mathrm{dt}$ were allowed to restabilize before reassessing the $R_{1} 60$ contractile response at the higher $[\mathrm{Ca}]_{\mathrm{e}}$. Additional experiments were performed in which calcium was added during the 60-s rest interval. Shown in Figure 5 is $R_{1} T$ following an incremental $(2.5 \mathrm{mM})$ increase in [Ca] during the rest interval compared with $R_{1} 60 \mathrm{~T}$ after stabilization with varying $[\mathrm{Ca}]_{\mathrm{e}}$. For the purposes of comparison, steady-state $\mathrm{T}$ following stabilization at the indicated $[\mathrm{Ca}]_{\mathrm{e}}$ are also shown in Figure 5. Increasing [Ca $]_{\mathrm{e}}$ from 2.5 to $5.0 \mathrm{mM}$ within the first 5 $\mathrm{s}$ of a 60-s rest interval (broken line) resulted in a small increase in $R_{1} T$ in atrial strips of both age groups. Although significant, these postrest tension responses were quantitatively less than the $[\mathrm{Ca}]_{\mathrm{e}}$-dependent changes seen in $\mathrm{R}_{1} 60 \mathrm{~T}$ response after stabilization with higher $[\mathrm{Ca}]_{\mathrm{e}}$ (solid line). Thus, a train of contractions appears necessary before the $[\mathrm{Ca}]_{\mathrm{e}}$-dependent increase in postrest contraction is fully manifested in the immature atria. 


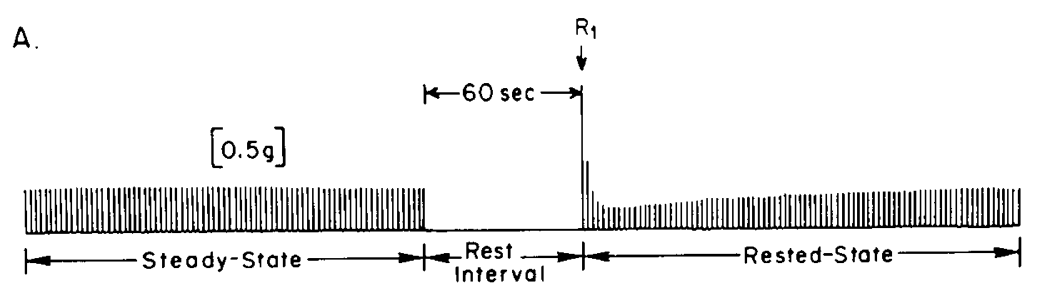

B.
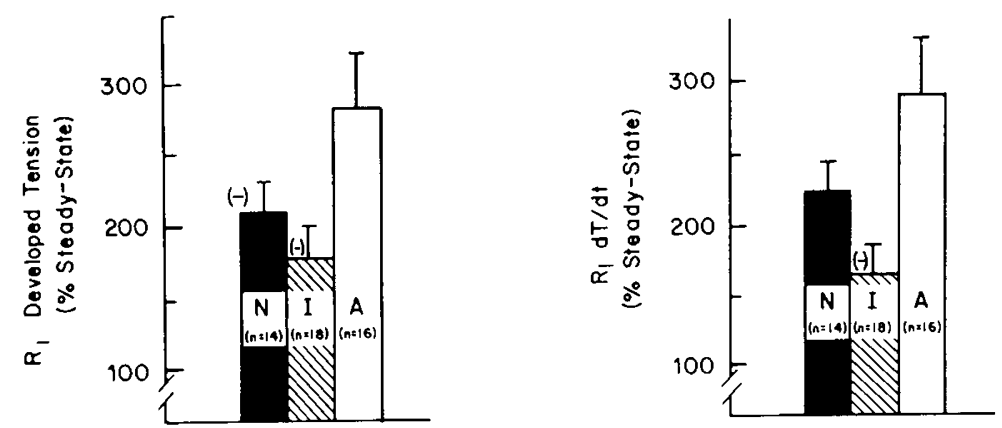

Fig. 2. Rest potentiation in rabbit atrial strips. Shown in $A$ is a representative tracing of the isometric tension $(T)$ developed by an adult atrial strip. Steady-state contraction at $1 \mathrm{~Hz}(l e f t)$ and the postrest contractile response following $60 \mathrm{~s}$ of rest and reinitiation of contraction at $1 \mathrm{~Hz}$ is shown (right). The first postrest contraction after 60 -s rest intervals is labeled as $\mathrm{R}_{1} 60 \mathrm{~s}$ in all subsequent figures. $B, \mathrm{R}_{1} 60 \Upsilon \mathrm{T}$ and $+\mathrm{dT} / \mathrm{dt}$, expressed as the percent steady-state $\mathrm{T}$ and $+\mathrm{dT} / \mathrm{dt}$, are shown for left atrial strips isolated from newborn $(N ; 1-7$ day old), immature $(I ; 14-21$ day old $)$, and adult ( $A ; \geq 6$ months) rabbit hearts. Following a 60 -s rest interval $\mathrm{R}_{1} \mathrm{~T}$ and $+\mathrm{dT} / \mathrm{dt}$ for all of these age groups were significantly greater (potentiated) relative to steady-state $\mathrm{T}$ and $+\mathrm{dT} / \mathrm{dt}$. (-) indicates values that are significantly less than adult (ANOVA; $p<0.05$ ) for the number of separate strips $(n)$ isolated from newborn and immature rabbit hearts.

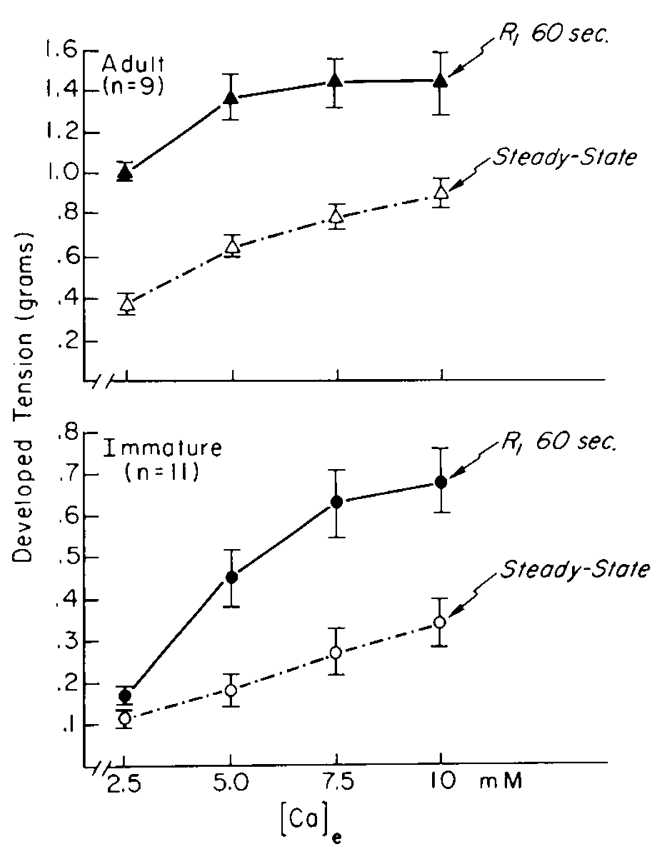

Fig. 3. Effect of $[\mathrm{Ca}]_{\mathrm{e}}$ on steady-state and rested-state tension. Steadystate $\mathrm{T}(\mathrm{O} ; \Delta)$ and $\mathrm{R}_{1} 60 \mathrm{~T}(\boldsymbol{\bullet} ; \mathbf{\Delta})$ for atrial strips isolated from adult (upper panel) and immature (lower panel) rabbit hearts are shown after stabilization at $2.5,5.0,7.5$, and $10.0 \mathrm{mM}[\mathrm{Ca}]_{\mathrm{c}}$.

To further determine if the $[\mathrm{Ca}]_{\mathrm{c}}$-dependent increase in postrest contraction of the immature atrial strip (Figs. 3 and 4) was due to increased intracellular accumulation of calcium, the effect(s) of other modalities that increase $[\mathrm{Ca}]_{i}$ were studied. Both increasing tonicity and isotonically reducing $[\mathrm{Na}]_{\mathrm{e}}$ have been reported to increase the force contraction and $[\mathrm{Ca}]_{i}(23)$. In

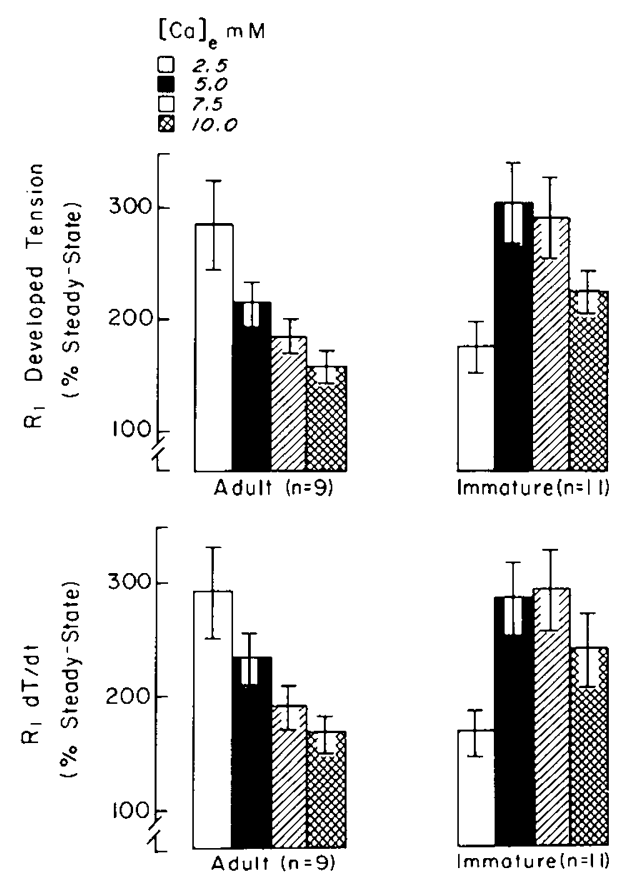

Fig. 4. Effects of $[\mathrm{Ca}]_{e}$ on postrest contraction. $\mathrm{R}, 60 \mathrm{~T}$ and $+\mathrm{dT} / \mathrm{dt}$ in immature and adult atrial strips are expressed as percent of steadystate T. (upper panel) or steady-state $+\mathrm{dT} / \mathrm{dt}$ (lower panel) after equilibration at $2.5,5.0,7.5$, and $10 \mathrm{mM}[\mathrm{Ca}]_{\mathrm{c}}$.

agreement with this premise, steady-state tension was increased both by hypertonic sucrose and reducing $[\mathrm{Na}]_{c}$, by isotonically shifting [Na] e from "control" (153 mM) to "low" (88 mM) $[\mathrm{Na}]_{e}$, in both immature and adult atrial strips (Fig. 6). Resting tension in both age groups were not changed from basal values 


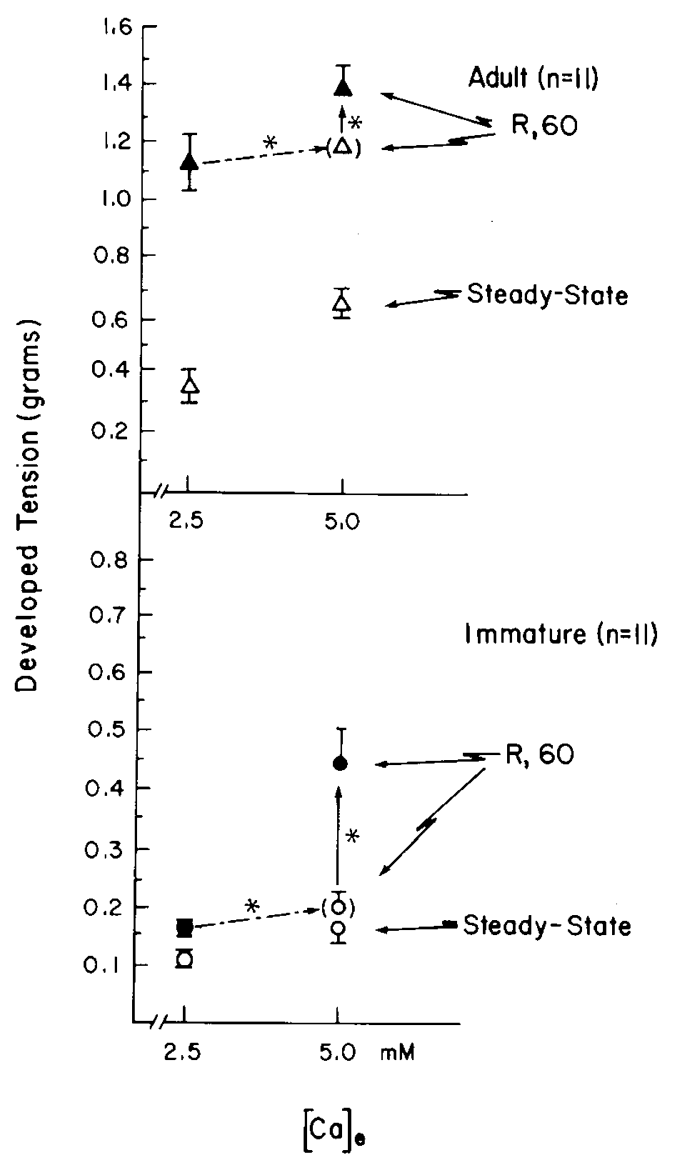

Fig. 5. Effects of calcium addition during 60-s rest Interval on postrest contraction. $\mathrm{R}, 60 \mathrm{~T}(\boldsymbol{\bullet} ; \boldsymbol{\Delta})$ and steady-state $\mathrm{T}(\mathrm{O} ; \Delta)$ developed by adult (triangles) and immature (circles) atrial strips are shown here after stabilization at 2.5 and $5.0 \mathrm{mM}[\mathrm{Ca}]_{\mathrm{e}}$ and after increasing $[\mathrm{Ca}]_{\mathrm{e}}$ to 5.0 $\mathrm{mM}$ during the first $5 \mathrm{~s}$ of the 60 -s rest interval indicated by the parentheses (). Increasing [Ca $]_{e}$ during the first rest interval is represented by the horizontal broken line. The subsequent effect of equilibration at $5.0 \mathrm{mM}[\mathrm{Ca}]_{\mathrm{e}}$ on $\mathrm{R}, 60 \mathrm{~T}$ is indicated by the vertical solid line. The asterisk indicates $R_{1} 60 \mathrm{~T}$ values that are significantly different from each other (paired $t$ test; $p<0.05$ ).

and were not different from those shown in Table 1 . When interpreting the effects on contraction of reducing $[\mathrm{Na}]_{\mathrm{e}}$ presented in Figure 6, it is important to note that the effects of hypertonicity or $[\mathrm{Na}]_{\mathrm{e}}$ on contraction are time-dependent and, to some extent, reversible (data not shown). Therefore the experimental results presented in Figure 6 were collected 30 min after changing the bath conditions. After bath tonicity was increased, steady-state tension had returned to near baseline before reducing $[\mathrm{Na}]_{\mathrm{e}}$. Thus despite similar steady-state tensions illustrated in Figure 6 for the immature groups under the conditions of hypertonic sucrose and reduced $[\mathrm{Na}]_{e}$, steady-state tension was increased in both immature and adult atrial strips.

Attention should be focused on two important comparisons pertinent to the age-related effects of increased tonicity and "low" $[\mathrm{Na}]_{\mathrm{e}}$ on postrest contraction. First, it is important to note the age-related differences in the magnitude of changes in postrest contraction after increasing tonicity. Both steady-state and postrest tension were increased in immature and adult atrial strips following the addition of hypertonic sucrose. However, in immature atrial strips hypertonicity had a greater effect on postrest contraction than steady-state contraction. The postrest potentiation of steady-state developed tension in hypertonic sucrose (303 $\pm 44 \%$ ) was greater than potentiation in the absence of sucrose $(188 \pm 30 \% ; n=7)$. Recall that postrest potentiation is a comparison of changes in postrest tension relative to changes in steady-state tension and for this comparison the $R_{1} 60 \mathrm{~T}$ values are expressed as the percent of steady-state tension. In contrast, in adult atrial strips hypertonicity had a smaller effect on postrest contraction than on steady-state contraction. Postrest potentiation of steady-state developed tension in hypertonic sucrose $(216$ $\pm 14 \%)$ was less than in the absence of sucrose $(384 \pm 84 \% ; n=$ 5).

Second, attention should be focused on age-related differences in postrest potentiation of tension before and after isotonically reducing $[\mathrm{Na}]_{e}$ in the presence of increased tonicity. In immature atria, reducing $[\mathrm{Na}]_{\mathrm{e}}$ had a greater effect on postrest contraction than on steady-state contraction (Fig. 6). In immature atrial strips postrest tension was further increased (approximately 2.4fold greater than baseline steady-state tension) after reducing $[\mathrm{Na}]_{\mathrm{e}}$ in the presence of increased tonicity (Fig. 6). In immature atrial strips, postrest potentiation of steady-state developed tension after lowering [Na $]_{e}(238 \pm 24 \%)$ was greater than potentiation before lowering $[\mathrm{Na}]_{\mathrm{e}}(188 \pm 26 ; n=8)$. In contrast, in adult atrial strips lowering $[\mathrm{Na}]_{\mathrm{e}}$ had a smaller effect on postrest contraction than steady-state contraction. The postrest potentiation values after lowering $[\mathrm{Na}]_{\mathrm{e}}(92 \pm 5 \%)$ was less than before lowering $[\mathrm{Na}]_{\mathrm{e}}(205 \pm 20 \% ; n=6)$. Thus, in immature atria postrest contraction, and presumably the loading and release of calcium from the SR, can be significantly augmented by conditions favoring calcium entry via $\mathrm{Na} / \mathrm{Ca}$ exchange. In contrast, in adult atria these same conditions have a relatively smaller effect on postrest contraction, possibly because calcium loading and/ or release of SR in adult atria is near maximum at $2.5 \mathrm{mM}$ $[\mathrm{Ca}]_{\text {e. }}$

The contractile response to ryanodine, a putative blocker of calcium release from the $\operatorname{SR}(12,15,17)$, was also evaluated. Steady-state tension at $5.0 \mathrm{mM}[\mathrm{Ca}]_{\mathrm{e}}$ was reduced by $5 \times 10^{-9}$ $M$ ryanodine both in immature $(0.19 \pm 0.03$ to $0.12 \pm 0.06 \mathrm{~g} ; n$ $=6)$ and adult $(0.74 \pm 0.07$ to $0.61 \pm 0.19 \mathrm{~g} ; n=5)$ atrial strips. Ryanodine reduced steady-state tension more in the immature than from the adult atrial strips ( $36 \pm 7 \%$ versus $18 \pm 3 \%$ of the

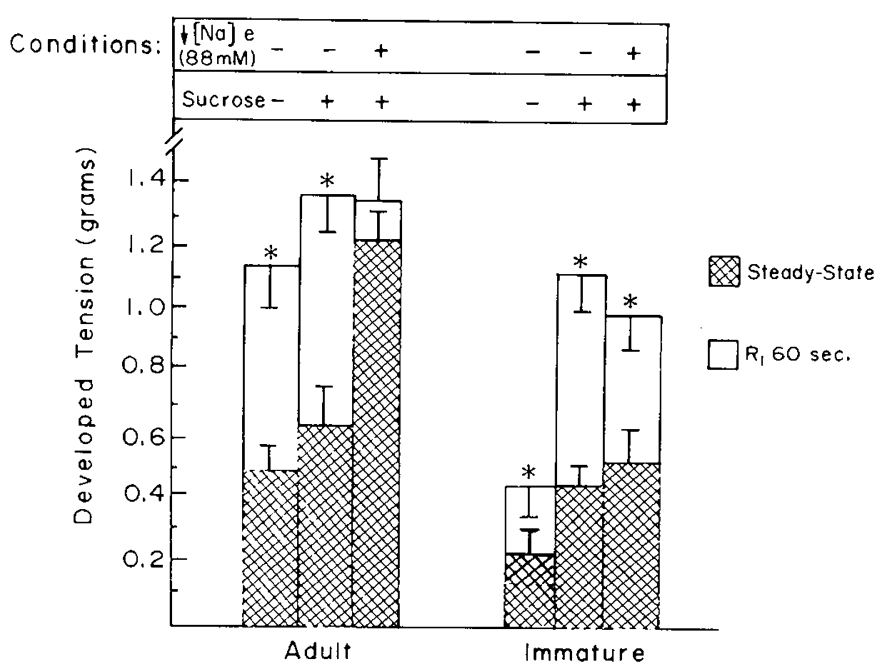

Fig. 6. Effects of tonicity and extracellular [ $\mathrm{Na}]$ on steady-state and rested-state contractions. The effect of increased osmolality equivalent to that of $120 \mathrm{mM}$ sucrose by the addition of solid sucrose and the additive effects of isomotically decreasing $[\mathrm{Na}]_{e}(87 \mathrm{mM})$ on steady-state and postrest developed tension are shown for atrial strips from adult (left) and immature (right) and rabbit heart. The asterisk indicates a significant (paired $t$ test; $p<0.05$ ) increase in $R_{1} 60 \mathrm{~T}$ relative to steadystate $\mathrm{T}$. 
pretreatment control steady-state tension; $p=0.05$ ). Postrest potentiation of contraction was completely blocked by $5 \times 10^{-9}$ $M$ ryanodine both in immature and adult atrial strips. $R_{1} 60$ tension in the presence of $5 \times 10^{-9} \mathrm{M}$ ryanodine was $78 \pm 28 \%$ and $102 \pm 20 \%$ of steady-state tension for immature and adult atrial strips, respectively. Thus postrest potentiation in both immature and adult atrial strips is ryanodine sensitive, supportive evidence that the age-related differences in postrest potentiation reflects rest time-dependent changes in calcium release from the SR.

\section{DISCUSSION}

Postrest contraction was studied to determine the ability of cardiac SR to release calcium during early postnatal development. Several independent lines of evidence indicate that augmented tension development of the first postrest contraction is due to increased calcium release from the SR. First, postrest potentiation of atrial contraction is abolished by ryanodine $(10$; present study), an alkaloid that inhibits the release of calcium from cardiac SR but does not directly affect the slow inward calcium current $(15,17)$. Conversely, inhibitors of the inward calcium current, such as cobalt or verapamil, do not inhibit atrial rest potentiation (10) (unpublished observations). Second, net transsarcolemmal calcium influx estimated by extracellular calcium depletion does not correlate with the force of the first postrest contraction, in contrast to the correlation observed for other inotropic interventions $(9,18)$. Third, it is unlikely that a rest would increase calcium influx since the slow inward calcium current and net calcium influx via the $\mathrm{Na} / \mathrm{Ca}$ exchange are depolarization dependent (14). Thus, substantial evidence has accumulated to indicate that potentiation of the first contraction after a rest interval is due to an increase in calcium release from the SR.

This study demonstrates rest potentiated contraction in rabbit atria during early postnatal development. Our results also demonstrate that a ryanodine-sensitive, calcium pool is responsible for rest-potentiated tension development in the developing rabbit atria. Thus our demonstration of postrest potentiation in both newborn and immature atrial strips provides evidence for calcium release from the $\mathrm{SR}$ in the early neonatal period.

An alternative interpretation of postrest potentiation is that the calcium sensitivity of the contractile elements may vary during the rest interval. However, this is unlikely since none of the experimental protocols used to alter postrest contraction in this study are known to affect cyclic AMP-dependent phosphorylation of the contractile elements, which is believed to be responsible for such changes in calcium sensitivity of the controctile elements (20).

This study has demonstrated that changing the ratio of extracellular calcium-to-sodium or increasing tonicity of the bath (Figs. 3 to 5) affects the age-related differences in postrest potentiation (Fig. 2). In view of the well-accepted relationship between inotropy, the ratio of extracellular calcium-to-sodium, and calcium loading of the SR $(14,22)$, we interpreted these results as evidence for age-related differences in calcium loading and/or of the SR. In support of this interpretation, the inotropic effects of increasing extracellular calcium-to-sodium ratio on postrest contraction of immature atrial strips was use dependent (Fig. 5).

The relative contributions of calcium released from the $S R$ and transsarcolemmal calcium influx to steady-state contraction is debated $(8,11,16)$. It remains uncertain whether or not transsarcolemmal calcium influx can directly contribute to contractile calcium. An additional goal of this study was to estimate the relative contribution of calcium release from the SR to steadystate contraction during postnatal development. Bers (11) has previously related the greater rest potentiation of contraction and the greater sensitivity of steady-state contraction to ryanodine to a greater dependency of contraction on calcium release from the SR. Following this line of reasoning, the smaller rest potentiation in the immature atria at $2.5 \mathrm{mM}$ [Ca]c (Fig. 2) suggests less contribution to contractile calcium by calcium released from the SR in immature atria. In our study of immature atrial strips, greater ryanodine sensitivity was apparent at the higher $[\mathrm{Ca}]_{\mathrm{c}}(5 \mathrm{mM})$ required to optimize postrest potentiation and presumably fully load the SR. In contrast, Penefsky (21) was unable to demonstrate ryanodine sensitive steady-state tension development in ventricular fibers from newborn rabbit heart. We speculate that at $5 \mathrm{mM}[\mathrm{Ca}]_{\mathrm{c}}$ the releasable pool of calcium in the SR is increased and its contribution of contractile calcium increased. Thus, the ryanodine "sensitivity" of steady-state contraction was actually greater in the immature than the adult. Whereas, at $2.5 \mathrm{mM}$ [Ca $]_{\mathrm{c}}$ the predominant source of contractile calcium for steady-state contraction in the developing heart may well be transsarcolemmal calcium influx because calcium loading and/or release from the SR is incomplete (13). (Fig. 1).

In summary, we observed significant age-related differences in postrest contractile responses which indicate that myocellular calcium regulation changes during postnatal cardiac development. These differences may be attributable to developmental differences in SR calcium uptake (24), the calcium releasing properties of the $\mathrm{SR}$, or in the functional interrelationship between the SR and the sarcolemma in the regulation of $[\mathrm{Ca}]_{i}$. Regardless of the mechanism, the net functional consequence of these differences is that immature atria require a higher $[\mathrm{Ca}]_{i}$ in order to maximize SR calcium loading and release.

Acknowledgments. The authors thank Dr. Sidney F. Fleischer for his critique of this manuscript and Joy Phillips and Barbara Hassler for their assistance in the preparation of the manuscript.

\section{REFERENCES}

1. Fabiato A and Fabiato F 1978 Calcium-induced release of calcium from the sarcoplasmic reticulum of skinned cells from adult nd newborn rat ventricles. Ann NY Acad Sci 307:491-522

2. Langer GA, Frank JS. Philipson KD 1982 Ultrastructure and calcium exchange of the sarcolemma, sarcoplasmic reticulum and mitochondria of the myocardium. J Pharmacol Ther 16:331-376

3. Page E, Buecker JL 1981 Development of dyadic junctional complexes between sarcoplasmic reticulum and plasmalemma in rabbit left ventricular myocardial cells: morphometric analysis. Circ Res 48:519-522

4. Maylie JG 1982 Excitation-contraction coupling in neonatal and adult myocardium of cat. Am J Physiol 242:H834-H943

5. Ishikawa $\mathrm{H}$ and Yamada $\mathrm{E} 1976$ Differentiation of the sarcoplasmic reticulum and T-system in developing Mouse Cardiac Muscle. In: Lierberman M, Sano $\mathrm{T}$ (eds) Development and Physiological Correlates of Cardiac Muscle. Raven Press, New York, pp 21-35

6. Boucek RJ, Jr, Shelton M, Artman M, Mushlin PS, Starnes V, Olson RD 1984 Comparative Effects of verapamil, nifedipine, and diltiazem on contractile function in the isolated immature and adult rabbit heart. Pediatr Res 18:948952

7. George BL, Jarmakani JM 1983 The effects of lanthanum and manganese on excitation-contraction coupling in the Newborn Rabbit Heart. Dev Pharmacol Ther 6:33-44

8. Reiter M, Vierling W, Seibel K 1984 Where is the origin of the activator calcium in cardiac ventricular contraction? Basic Res Cardiol 79:1-8

9. Hilgemann DW, Delay MJ, Langer GA 1983 Activation-dependent cumulative depletions of extracellular free calcium in guinea pig atrium measured with antipyrylazo III and tetramethylmurexide. Circ Res 53:779-793

10. Temma K, Akera T, Brody TM 1981 Inotropic effects of digitoxin in isolated guinea-pig heart under conditions which alter contraction. Eur J Pharmacol $76: 361-370$

11. Bers D $1985 \mathrm{Ca}$ Influx and sarcoplasmic reticulum Ca release in cardiac muscle activation during postrest recovery. Am J Physiol 248:H366-H381

12. Frank M. Sleaton WW 1975 Effect of ryanodine on myocardial calcium. Arch Pharmacol 290:35-47

13. Vornanen M 1985 Effect of strontium on the contractile properties of postnatally developing rat heart ventricles. Can J Physiol Pharmacol 63:9-17

14. Sutko JL, Bers DM, Reeves JP 1986 Postrest inotropy in rabbit ventricle: $\mathrm{Na}^{+}$$\mathrm{Ca}^{2+}$ exchange determines sarcoplasmic reticulum $\mathrm{Ca}^{2+}$ content. Am J Physiol 19:H654-H661

15. Sutko JL, Kenyo JL 1983 Ryanodine modification of cardiac muscle responses to potassium-free solutions: evidence for inhibition of sarcoplasmic reticulum calcium release. J Gen Physiol 82:385-404 
16. Lewartowski B, Pytkowski B, Janczewski A 1984 Calcium fraction correlating with contractile force of ventricular muscle of guinea-pig heart. Eur J Physiol 401:198-203

17. Sutko JL, Willerson JT 1980 Ryanodine alteration of the contractile state of rat ventricular myocardium. Circ Res 46:332-343

18. Tillisch JH, Fung LK, Hom PM, Langer GA 1979 Transient and steady-state effects of sodium and calcium on myocardial contractile response. J Mol Cell Cardiol 11:137-148

19. Bers DM 1983 Early transient depletion of extracellular Ca during individual cardiac muscle contractions. Am J Physiol 244:H462-H468

20. Ezrailson EG, Potter JD, Michael L, Schwartz A 1977 Positive inotropy induced by ouabain, by increased frequency, by X537A (R02-2985), by calcium and by isoproterenol: the lack of correlation with phosphorylation of TnI. J Mol Cell Cardiol 9:693-698

21. Penefsky ZJ 1974 Studies on mechanism of inhibition of cardiac muscle contractile tension by ryanodine. Pflugers Arch 347:173-184

22. Li T, Vassalle M 1983 Sodium-calcium exchange in Purkinje fibers: electrical and mechanical effects. Basic Res Cardiol 78:396-414

23. Lado MG, Sheu SS, Fozzard HA 1984 Effects of tonicity on tension and intracellular sodium and calcium activities in sheep heart. Circ Res 54:576-
585

24. Nayler WG, Fassold E 1977 Calcium accumulating and ATPase activity of cardiac sarcoplasmic reticulum before and after birth. Cardiovasc Res 2:231237 